\title{
Uterine Artery Doppler and Placental Morphological Features as Predictors of Peripartum Complications in Placenta Previa and Placenta Previa Accreta
}

\author{
Shimaa F. Eliwa, Mahmoud Abdel Fatah, Mohamed A. El Noury, Mostafa A. El Sayed
}

Department of Obstetrics and Gynecology, Benha faculty of medicine, Banha University, Egypt.

Correspondence to: Shimaa F. Eliwa, Department of Obstetrics and Gynecology, Benha faculty of medicine, Banha University, Egypt.

Email:

eshimaa441@gmail.com

Received: 25 February 2020

Accepted: 22 March 2020

\begin{abstract}
:
Background: Placenta accreta is becoming an increasingly common complication of pregnancy. Placenta accreta originates from abnormal trophoblast invasion. Objective: to assess if uterine artery Doppler and Placental Morphological Features could be predictors of maternal and fetal outcome in pregnancies complicated with placenta previa and placenta previa accreta. Subjects and methods: This study included 80 pregnant women of which they were divided into 3 groups. The first group included 40 pregnant women of normal pregnancies, $2^{\text {nd }}$ one included 20 pregnant women with placenta previa and the $3^{\text {rd }}$ one included 20 pregnant women with suspected placenta previa accreta by ultrasound. Abdominal ultrasound and uterine artery Doppler were done in a week before delivery. Results: There was a direct relationship between presence of lacunae especially high grade, placental vascularity (abnormal) and the mean values of uterine artery PI, RI and presence of
\end{abstract} peripartum maternal and fetal complications. Conclusion: the gray scale and color Doppler ultrasound have a high diagnostic value in the diagnosis by certain placental morphological features, Including loss of retro-placetal clear zone, thinning of myometrial thickness, Intraplacental lacunae, Intraplacental vascularity and exophytic mass into bladder space. Ultrasound is helpful and non-invasive tool in prediction of maternal and fetal outcome. High grade of placental lacunae and abnormal placental vascularity were highly associated with maternal and fetal complications. Uterine artery Doppler PI and RI is also useful in prediction of maternal complications and fetal complications of placenta previa and placenta previa accreta.

Keywords: Placental Morphological Features, Uterine Artery Doppler, Placenta accreta.

Abbreviation: pulsatility index $(\mathrm{PI})$ - resistive index $(\mathrm{RI})$ 


\section{Introduction}

Placenta accreta is becoming an increasingly common complication of pregnancy. Morbidly adherent placenta (MAP) incidence has increased nearly 10 -fold over the last 50 years ${ }^{(1)}$. Placenta accreta remains the most common reason for Caesarean hysterectomy in developed countries ${ }^{\text {(3) }}$. Maternal mortality for the most severe end of the AIP spectrum (placenta percreta) has been reported to be as high as $7 \%{ }^{(2)}$. The major contributing factor is thought to be the increased rate of cesarean delivery. Patients with MAP clearly are at an increased risk for massive bleeding, dilutional and consumptive coagulopathy, massive transfusion, multiorgan failure, and death. In addition, surgical complications such as bladder, ureteric, and bowel injury are not uncommon $^{(4)}$. Detection of placenta accreta is important for the development of an effective treatment strategy to minimize maternal morbidity and mortality. Placenta accreta is diagnosed with gray-scale and color Doppler sonography. The sonographic signs suggestive of placenta accreta include the presence of placental vascular lacunae, abnormal placental vascularity loss of an anechoic area, interruption of the bladder uterine serosa, visualization of a focal protruding mass, and high velocity pulsatile blood flow between the placenta and bladder. However, these signs are difficult to detect in the clinical setting because of the subjectivity involved in their interpretation. Therefore, a more objective tool that can enable accurate diagnosis of placenta accreta while minimizing interoperator variability is necessary. Placenta accreta originates from abnormal trophoblast invasion. In addition, previous uterine artery Doppler studies have suggested that uterine artery resistive index $(\mathrm{RI})$ is reduced in placenta accrete. ${ }^{(6)}$ The current study aimed to assess if uterine artery Doppler and Placental Morphological Features could be predictors of maternal and fetal outcome in pregnancies complicated with placenta previa and placenta previa accreta.

\section{Material and Methods}

\section{Technical design:}

(I) Study design: A prospective observational clinical study at Obstetrics and Gynaecology Department in Benha University and in Kafr-Shukr Hospital from March 2018 to September 2019.

(II) Sample size: 80 pregnant women; assigned into 3 groups:

i. Group A including 40 pregnant women with normal pregnancy. 
ii. Group B including 20 pregnant women with placenta previa.

iii. Group C including 20 pregnant women with placenta previa with placental morphological features of placenta accreta.

\section{(III) Inclusion criteria:}

Singleton pregnancies, women bearing a living fetus, gestational age ranging between 34 and 37 weeks calculated from first day of LNMP or by a first trimester $\mathrm{U} / \mathrm{S}$, patients with no coexisting medical disorders and patient acceptance to join the study after signing an informed consent.

\section{(IV) Exclusion criteria:}

Multifetal pregnancies or pregnancies with IUFD associated other medical conditions as pregnancy-induced hypertension, heart diseases and rheumatological diseases apart from iron deficiency anemia, prelabor ROM, presence of diagnosed fetal anomalies and patients who refuse to take part in the study.

\section{* Methods:}

\section{1- Ethical consideration}

For each patient included in the study, a written informed consent was taken after explaining the nature of the study. All patients were subjected to:

\section{2- A detailed history taking:}

Personal history (Name, age and file number), past and present history, obstetric history, obstetric code and mode of delivery, gestational age by date and first trimesteric ultrasound, past obstetric history including recurrent miscarriage, preterm delivery, preeclampsia, unexplained stillbirth.

3- Full general and abdominal examination.

\section{4- Routine baseline laboratory investigations:}

Preoperative laboratory investigations from medical records of the cases including blood type, Rh status, CBC, INR, PT, PTT, liver function tests, kidney function tests, FBG and $2 \mathrm{~h}$ PP.

\section{5- Ultrasonography evaluation:}

The women were placed in supine position and examination was performed with the bladder partially filled which allows optimal visualization of the uterine serosa and the bladder wall. US detect:

1) Fetal viability.

2) Fetal maturity.

3) Fetal age.( by assessment of bi-parietal diameter and femur length).

4) Fetal weight.

5) Amniotic fluid.

6) Location of the placenta.

Diagnosis of total and margin placental previa was made when either the internal 
cervical OS was completely covered by placenta or the leading edge of the placenta was less than $2 \mathrm{~cm}$ from the internal OS, but not fully covered by the placenta, respectively ${ }^{(7)}$.

- Ultrasound findings suggestive of placenta accreta assesses:

1- Absence of retroplacental sonolucent zone.

2- Vascular interplacental lacunae.

3- Myometrial thinning (loss of bladder wall - uterine interface).

4- Pattern of vascularity.

5- Presence of focal exophytic mass invading the bladder. ${ }^{(8)}$

We evaluated echolucent area between uterus and placenta (intact, absent) according to Comstock et al., (9) and bladder wall-uterine interface (intact, interrupted) according to Comstock et al., (9) and Esakoff et al., ${ }^{(10) .}$ The vascularity of placenta on color Doppler was classified as normal and abnormal intraplacental vascularity and severe uteroplacental hypervascularity according to Woodring et al., (11). Intraplacenal lacunae was 0 when none was seen, 1 when one to three generally small lacunae were present, 2 when four to six larger or more irregular lacunae were present, and 3 when there were many throughout the placenta, some appearing large and irregular shape ${ }^{(12)}$.
6-Doppler studies of both uterine arteries were made according to Kwak et al., ${ }^{(13) .}$

- Color Doppler findings of placenta accreta:

Diagnosis of placenta accreta depends on presence of one or more of these findings: Turbulent blood flow extending from the placenta into surroundings:

1- A diffuse lacunar flow pattern exhibiting diffusely dilated vascular channels scattered throughout the whole placenta and the surrounding myometrial or cervical tissues. High-velocity pulsatile venous-type flow is found in the sonolucent vascular spaces.

2- Interface hypervascularity with abnormal blood vessels linking the placenta to the bladder with high diastolic arterial blood flow.

3- Markedly dilated peripheral subplacental vascular channels with pulsatile venoustype flow over the uterine cervix.

\section{Imaging protocols:}

TAS and TVS were done for the patients using Voluson 730 Pro V machine with colour Doppler (GE Healthcare, Austria), equipped with a $3.5 \mathrm{MHz}$ sector transducer for TAS, and $7.5 \mathrm{MHz}$ transvaginal transducer for TVS. 


\section{Transabdominal scanning:}

All examination was performed while the mother in the supine position with her urinary bladder partially filled so as not to distort the configuration of the cervix or lower uterine segment. The gestational age was determined by measurement of the Biparietal Diameter (BPD) and Femur Length (FL). Sonographic evaluation of placenta previa requires visualization of both the cervix and the lower edge of the placenta.

\section{Doppler study:}

The uterine artery identified by placing the transducer in lower lateral quadrant of the uterus and by angling it medially, an apparent crossover of the external iliac artery and vein, and the main uterine artery can be identified by the typical high velocity pattern. The artery of the same side of the placental location was named placental uterine, and the other side, the non-placental uterine artery.

\section{- Monitoring the outcome:}

The outcome of this study was measured by the occurrence of peripartum complications in both mother and fetus.

\section{Maternal complications:}

Maternal mortality - Maternal morbidity (blood transfusion, bladder injuries, CS hysterectomy and ICU admission).

\section{Neonatal complications:}

Low birth weight - Apgar score at 1 and 5 minutes - NICU admission - Neonatal mortality.

Statistical analyses: The clinical data recorded on a report form. These data were tabulated and analyzed using the computer program SPSS (statistical package for social science) Version 20.0. Armonk, NY: IBM Corp. to obtain. Descriptive statistics were calculated for the data in the form of frequency and distribution for qualitative data. Analytical statistics: In the statistical comparison between the different groups, the significance of difference was tested using one of the following tests:-Inter-group comparison of categorical data was performed by using chi square test $\left(\mathrm{X}^{2}-\right.$ value) and fisher exact test (FET). Spearman correlation test used to detect significant correlation between quantitative variables. Age, gravidity, parity, type of delivery placenta retro placental sonolucent zone, retro placental space hyper-echoic serosal bladder interface, exophytic mass invading bladder, placenta lacunae, color Doppler findings, RT.PI, RT.RI, LT.PI and LT.RI, 
were entered the binary logistic regression model, stepwise method was used, to detect the significant predictors of peripartum complications. $\mathrm{P}$ value $<0.05$ was considered statistically significant $(*)$ while $>0.05$ statistically significant $\mathrm{P}$ value $<0.01$ was considered highly significant $(* *)$ in all analyses.

\section{Result:}

There was significant difference between mean ages of the studied groups. Where mean age of group (C) was significantly higher than mean age of group (A) $\{32.95$ vs. 28.33\}.mode of delivery was significantly different between the three group, C.S reported at higher proportion among group (C) compared to group (A) with $\mathrm{P}$ value $<0.001$.Gravidity and parity show no significant difference in the three groups. There was high significant relation between the mean value of uterine artery PI and RI in the three groups. There were high significant relations between CS hysterectomy, blood transfusion, ICU, NICU, Preterm labor and bladder injury and the 3 groups also there was a significant relations between Maternal mortality and Neonatal death.

\section{Discussion}

The present study showed that, there were maternal deaths (2 cases) which were among group C (10\%). This is in disagreement with a study (15) which found that, maternal mortality had been reported to occur in up to $60 \%$ of women with placenta accreta. However due to proper planning we have much lower rates. (Table 3). In the current study, CS hysterectomies were significantly higher in group $\mathrm{C}$ than (group B and group A). $(\mathbf{P}<\mathbf{0 . 0 0 1})$. This is in agreement with others (16) who found that, as placenta accretas have increased, the indications for CS hysterectomy have changed, with accreta accounting for up to $47 \%$ of indications. (Table 4).

In the current study, fetal complications (neonatal death, admission to NICU and preterm labor were significantly higher in (Group B and Group C) than Group A. This agrees with a study by some researchers ${ }^{(17)}$ where it was reported that, adverse perinatal outcomes were also reported with placenta previa/accreta including: admission to NICU, low birth weight (< $2500 \mathrm{~g})$, IUGR, and increased risk for sudden infant death syndrome (SIDS). We found that significant relation between lacunae and CS hysterectomy, blood transfusion, ICU and bladder injury with (p value less than 0.001), with no significance with maternal mortality, also we found that there was a significant relation between lacunae and fetal complications (Table 4 ). This agrees 
with the study done by Korean researchers (18) who found that in cases where lacunae are seen, the incidence of maternal complications such as massive transfusion, admission to the intensive care unit and Cesarean hysterectomy related to massive intraoperative bleeding increases significantly.

Thus, the existence of intraplacental lacunae in patients with placenta previa and placenta accreta, can be useful in determining the patient's clinical outcome, as well as in counseling the patient, and in preparing her for surgery. This study showed that, as blood transfusion increased in patients who had lacunae types $2,3 \& 4$. CS hysterectomy also increased in patients who had lacunae especially types $3 \& 4$ and a high rate of ICU admission was with presence of lacunae types $3 \& 4$ with $(\mathbf{p}$ value $<\mathbf{0 . 0 0 1})$ a statistically significant effect (Table 4). This agrees with other scientists ${ }^{(\mathbf{1 2})}$ who not only described the mere presence of such placental lacunae but also their grading. The current study shows significant relations between placental vascularity and CS hysterectomy, Blood transfusion, ICU and Bladder injury with (p value less than 0.001). It was found that abnormal placental pulsatility index (PI) and right and left resistive index (RI) were significantly lower in the accreta group than previa group. This vascularity were associated with CS hysterectomy, blood transfusion, bladder injury, ICU admission with (p value < 0.001) a statistically significant effect (Table 5).

This is in agreement with a study done on 2011 (19) which found that, increased placental vascularity was associated with CS hysterectomy, blood transfusion, bladder injury and ICU admission, and with another (12) which revealed that, uteroplacental hypervascularity was significantly associated with a higher risk of cesarean hysterectomy, blood transfusion and peripartum complications. This study showed that, variations in trans-abdominal gray ultrasound findings (Loss of retroplacental sonolucent zone, Thinning or disruption of hyper-echoic serosal bladder interface and Presence of focal exophytic mass invading the bladder) were associated with group C. (Table 6). Previous studies proved the association between the ultrasonographic findings of this lack of a clear zone and the adherence of the placenta (Table 6). This is in agreement with other study ${ }^{(19}$.).Our study showed that, the mean values of right and left uterine artery

agrees with a study, ${ }^{(16)}$ which reported that the mean uterine artery PI was significantly lower in the placenta accreta group 
compared to previa alone (0.51 versus 0.57 ; $\mathrm{P}=.002)$. Their study suggests that the mean PI measured by uterine artery Doppler velocimetry is reduced in patients with placenta accreta compared to those without accreta.

The diagnostic accuracy of placenta accreta can be potentially improved if uterine artery Doppler values and the history of cesarean delivery are combined, (Table 8). The present study showed that there are significant relations between maternal complications (CS hysterectomy, blood transfusion, ICU admission, bladder injury) and the mean values of right and left (RI), and no significance difference between occurrence of neonatal death and the mean values of uterine artery (PI) and right and the mean values of (RI). This disagrees with a study (21) which reported that the mean uterine artery PI was related to intrauterine growth restriction, placenta abruption, and intrauterine fetal death.

(Table 7 and 8). Our study findings showed that the mean values of uterine artery RI was decreased in patients with placenta accreta. This is in agreement also with the study ${ }^{(6)}$ which revealed that uterine artery Doppler $\mathrm{RI}$ is reduced in placenta accreta patients when compared with placenta previa or normal pregnancy. Consequently, uterine artery Doppler velocimetry can be a useful tool for predicting placenta accreta. (Table 2).

The present study showed that as an increase uterine artery PI had significant association with CS hysterectomy, ICU and Bladder injury with (p values of $0.02,0.008$ and 0.01) respectively. (Table 7). The present study showed that left resistive index (RI) was significant predictor for C.S hysterectomy (Table 9).

This is in agreement with that study (24) which aimed to detect the accuracy of the Doppler in the diagnosis of morbid adherent placenta (MAP). They found that, Retro placental sonolutent zone (Loss) was significant predictor for ICU admission. This agrees also with other studies (18) (21) (21) (25) which reported that Retro placental sonolutent zone (Loss) was significant predictor admission to the intensive care unit and for fetal weight. The present study showed that Placental vascularity (abnormal) was significant predictor for fetal weight. 
Table (1): Uterine artery PI\& RI in relation to the 3 groups

\begin{tabular}{|c|c|c|c|c|c|}
\hline $\begin{array}{l}\text { Group } \\
\text { Uterine artery }\end{array}$ & $\begin{array}{l}\text { Group A } \\
(\mathrm{N}=40) \\
\text { Mean } \pm \text { SD }\end{array}$ & $\begin{array}{l}\text { Group B } \\
(\mathrm{N}=20) \\
\text { Mean } \pm \text { SD } \\
\end{array}$ & $\begin{array}{l}\text { Group C } \\
(\mathbf{N}=\mathbf{2 0}) \\
\text { Mean } \pm \text { SD }\end{array}$ & $\mathbf{F}$ & $\mathbf{P}$ \\
\hline Rt. PI & $1.24 \pm 0.45$ & $1.37 \pm 0.34$ & $0.87 \pm 0.31$ & 8.776 & $<0.001(\mathrm{HS})$ \\
\hline Rt. RI & $0.69 \pm .18$ & $0.84 \pm 0.22$ & $0.49 \pm 0.13$ & 18.944 & $<0.001(\mathrm{HS})$ \\
\hline It. PI & $1.10 \pm .34$ & $1.20 \pm 0.35$ & $0.90 \pm 0.29$ & 4.458 & $0.01(\mathrm{~S})$ \\
\hline It. RI & $0.64 \pm 0.14$ & $0.72 \pm 0.15$ & $0.41 \pm 0.09$ & 31.234 & $<0.001(\mathrm{HS})$ \\
\hline
\end{tabular}

Table (2): Maternal and Fetal complications among the studied 3 groups.

\begin{tabular}{|c|c|c|c|c|c|c|c|c|c|}
\hline \multirow{2}{*}{$\begin{array}{l}\text { Geripartum } \\
\text { complications }\end{array}$} & & \multicolumn{2}{|c|}{$\begin{array}{l}\text { Group A } \\
(\mathrm{N}=\mathbf{4 0})\end{array}$} & \multicolumn{2}{|c|}{$\begin{array}{l}\text { Group B } \\
(\mathbf{N}=20)\end{array}$} & \multicolumn{2}{|c|}{$\begin{array}{l}\text { Group C } \\
(\mathrm{N}=\mathbf{2 0})\end{array}$} & \multirow{2}{*}{$\begin{array}{l}\mathrm{X}^{2} / \\
\text { FET }\end{array}$} & \multirow[t]{2}{*}{$\mathbf{P}$} \\
\hline & & No. & $\%$ & No. & $\%$ & No. & $\%$ & & \\
\hline \multirow{2}{*}{ Maternal mortality } & Yes $(\mathrm{N}=2)$ & $\overline{0}$ & 0.0 & $\overline{0}$ & 0.0 & 2 & 90.0 & \multirow[b]{2}{*}{6.1} & \multirow{2}{*}{$\begin{array}{l}0.04 \\
(\mathrm{~S})\end{array}$} \\
\hline & No $(\mathbf{N}=78)$ & 40 & 100.0 & 20 & 100.0 & 18 & 10.0 & & \\
\hline \multirow{2}{*}{ CS hysterectomy } & Yes $(N=15)$ & 0 & 0.0 & 2 & 90.0 & 13 & 65.0 & \multirow{2}{*}{38.3} & $<0.001$ \\
\hline & No $(\mathbf{N}=65)$ & 40 & 100.0 & 18 & 10.0 & 7 & 35.0 & & (HS) \\
\hline \multirow{2}{*}{ Blood transfusion } & Yes $(\mathrm{N}=32)$ & 0 & 0.0 & 12 & 60.0 & 20 & 100.0 & \multirow{2}{*}{60.0} & $<0.001$ \\
\hline & No $(\mathbf{N}=48)$ & 40 & 100.0 & 8 & 40.0 & 0 & 0.0 & & (HS) \\
\hline \multirow{2}{*}{ ICU } & Yes $(\mathrm{N}=14)$ & 0 & 0.0 & 1 & 5.0 & 13 & 65.0 & \multirow{2}{*}{41.9} & $<0.001$ \\
\hline & No $(\mathbf{N}=66)$ & 40 & 100.0 & 19 & 95.0 & 7 & 35.0 & & $(\mathrm{HS})$ \\
\hline \multirow{2}{*}{ Bladder injury } & Yes $(\mathrm{N}=40)$ & 0 & 0.0 & 0 & 0.0 & 10 & 50.0 & \multirow{2}{*}{34.2} & \multirow{2}{*}{$\begin{array}{l}<0.001 \\
(\mathrm{HS})\end{array}$} \\
\hline & No $(\mathbf{N}=16)$ & 40 & 10.0 & 20 & 100.0 & 10 & 50.0 & & \\
\hline \multirow{2}{*}{ Neonatal death } & Yes $(N=6)$ & 0 & 0.0 & 3 & 15.0 & 3 & 15.0 & \multirow{2}{*}{6.48} & 0.03 \\
\hline & No $(N=74)$ & 40 & 100.0 & 17 & 85.0 & 17 & 85.0 & & $(\mathrm{~S})$ \\
\hline \multirow{2}{*}{ NICU } & Yes $(N=21)$ & 0 & 0.0 & 8 & 40.0 & 13 & 65.0 & \multirow{2}{*}{31.7} & $<0.001$ \\
\hline & No $(\mathbf{N}=59)$ & 40 & 100.0 & 12 & 60.0 & 7 & 35.0 & & (HS) \\
\hline \multirow{2}{*}{ Preterm labor } & Yes $(N=24)$ & 0 & 0.0 & 10 & 50.0 & 14 & 30.0 & \multirow{2}{*}{36.1} & $<0.001$ \\
\hline & Yes $(N=6)$ & 40 & 100.0 & 10 & 50.0 & 6 & 70.0 & & (HS) \\
\hline
\end{tabular}

Table (3): Relation between lacunae, maternal and FETAL peripartum complications.

\begin{tabular}{|c|c|c|c|c|c|c|c|c|c|c|c|c|c|}
\hline \multirow[t]{2}{*}{ Variable $(N=80)$} & & \multicolumn{2}{|c|}{$\begin{array}{l}\text { Lacunae } \\
0 \\
(\mathrm{~N}=22)\end{array}$} & \multicolumn{2}{|c|}{$\begin{array}{l}1 \\
(\mathrm{~N}=19)\end{array}$} & \multicolumn{2}{|c|}{$\begin{array}{l}2 \\
(N=17)\end{array}$} & \multicolumn{2}{|c|}{$\begin{array}{l}3 \\
(\mathrm{~N}=9)\end{array}$} & \multicolumn{2}{|c|}{$\begin{array}{l}4 \\
(N=13)\end{array}$} & \multirow{2}{*}{$\begin{array}{l}\mathrm{X}^{2} / \\
\text { FET }\end{array}$} & \multirow[t]{2}{*}{$\mathbf{P}$} \\
\hline & & No. & $\%$ & No. & $\%$ & No. & $\%$ & No. & $\%$ & No. & 7 & & \\
\hline \multirow{6}{*}{$\begin{array}{l}\text { Maternal } \\
\text { mortality } \\
\text { CS } \\
\text { hysterectomy } \\
\text { Blood } \\
\text { transfusion }\end{array}$} & Yes $(\mathrm{N}=2)$ & 0 & 0.0 & 0 & 0.0 & 0 & 0.0 & 1 & 11.1 & 1 & 7.7 & \multirow{2}{*}{5.6} & \multirow{2}{*}{0.22} \\
\hline & No $(\mathbf{N}=78)$ & 22 & 100 & 19 & 100.0 & 17 & 100.0 & 8 & 88.9 & 12 & 92.3 & & \\
\hline & Yes $(N=15)$ & 0 & 0.0 & 2 & 10.5 & 0 & 0.0 & 6 & 66.7 & 7 & 53.8 & \multirow{2}{*}{33.9} & \multirow{2}{*}{$\begin{array}{l}<0.001 \\
(\mathrm{HS})\end{array}$} \\
\hline & No $(\mathbf{N}=65)$ & 22 & 100 & 17 & 89.5 & 17 & 100.0 & 3 & 33.3 & 6 & 46.2 & & \\
\hline & Yes $(\mathrm{N}=32)$ & 2 & 9.1 & 3 & 15.8 & 6 & 35.3 & 8 & 88.9 & 13 & 100.0 & \multirow{2}{*}{42.01} & \multirow{2}{*}{$\begin{array}{l}<0.001 \\
\text { (HS) }\end{array}$} \\
\hline & No $(\mathbf{N}=48)$ & 20 & 90.9 & 16 & 84.2 & 11 & 64.7 & 1 & 11.1 & 0 & 0.0 & & \\
\hline \multirow{2}{*}{ ICU } & Yes $(\mathrm{N}=14)$ & 0 & 0.0 & 1 & 5.3 & 0 & 0.0 & 2 & 22.2 & 11 & 84.6 & 500 & $<0.001$ \\
\hline & No $(\mathbf{N}=66)$ & 22 & 100.0 & 18 & 94.7 & 17 & 100.0 & 7 & 77.8 & 2 & 15.4 & 50.9 & (HS) \\
\hline \multirow{2}{*}{ Bladder injury } & Yes $(\mathrm{N}=40)$ & 0 & 0.0 & 0 & 0.0 & 0 & 0.0 & 2 & 22.2 & 8 & 61.5 & \multirow{2}{*}{37.6} & $<0.001$ \\
\hline & No $(N=16)$ & 22 & 100.0 & 19 & 100.0 & 17 & 100.0 & 7 & 77.8 & 5 & 38.5 & & (HS) \\
\hline \multirow{2}{*}{ Neonatal death } & Yes $(\mathrm{N}=6)$ & 0 & 0.0 & 1 & 5.3 & 0 & 0.0 & 2 & 22.2 & 3 & 23.1 & \multirow{2}{*}{10.6} & 0.03 \\
\hline & No $(N=74)$ & 22 & 100.0 & 18 & 94.7 & 17 & 100.0 & 7 & 77.8 & 10 & 76.9 & & $(\mathrm{~S})$ \\
\hline \multirow{2}{*}{ NICU } & Yes $(\mathrm{N}=21)$ & 2 & 9.1 & 3 & 15.8 & 2 & 11.8 & 5 & 55.6 & 9 & 69.2 & \multirow{2}{*}{22.6} & $<0.001$ \\
\hline & No $(\mathrm{N}=59)$ & 20 & 90.9 & 16 & 84.2 & 15 & 88.2 & 4 & 44.4 & 4 & 30.8 & & (HS) \\
\hline \multirow[t]{2}{*}{ Preterm labor } & Yes $(\mathrm{N}=24)$ & 2 & 9.1 & 4 & 21.1 & 3 & 17.6 & 5 & 55.6 & 10 & 76.9 & \multirow{2}{*}{22.9} & $<0.001$ \\
\hline & No $(\mathrm{N}=56)$ & 20 & 90.9 & 15 & 78.9 & 14 & 82.4 & 4 & 44.4 & 3 & 23.1 & & (HS) \\
\hline
\end{tabular}


Table (4): The relationship between placental vascularity and maternal peripartum complications.

\begin{tabular}{|c|c|c|c|c|c|c|c|}
\hline \multirow[b]{2}{*}{ Mat. complications } & \multirow[t]{2}{*}{ Vascularity } & \multicolumn{2}{|c|}{$\begin{array}{l}\text { Normal } \\
(\mathrm{N}=50)\end{array}$} & \multicolumn{2}{|c|}{$\begin{array}{l}\text { Abnormal } \\
(\mathbf{N}=\mathbf{3 0})\end{array}$} & \multirow{2}{*}{$\begin{array}{l}\mathbf{X}^{2} / \\
\text { FET }\end{array}$} & \multirow[t]{2}{*}{$\mathbf{P}$} \\
\hline & & No. & $\%$ & No. & $\%$ & & \\
\hline \multirow{2}{*}{ Maternal mortality } & Yes $(\mathrm{N}=2)$ & 0 & 0.0 & 2 & 6.7 & \multirow{2}{*}{3.41} & \multirow{2}{*}{0.06} \\
\hline & No $(\mathbf{N}=78)$ & 50 & 100.0 & 28 & 93.3 & & \\
\hline \multirow{2}{*}{ CS hysterectomy } & Yes $(\mathrm{N}=15)$ & 1 & 2.0 & 14 & 46.7 & \multirow{2}{*}{24.55} & $<0.001$ \\
\hline & No $(\mathbf{N}=65)$ & 49 & 98.0 & 16 & 53.3 & & (HS) \\
\hline \multirow{2}{*}{ Blood transfusion } & Yes $(\mathrm{N}=32)$ & 8 & 16.0 & 24 & 80.0 & \multirow{2}{*}{32.0} & $<0.001$ \\
\hline & No $(\mathbf{N}=48)$ & 42 & 84.0 & 6 & 20.0 & & (HS) \\
\hline \multirow{2}{*}{ ICU } & Yes $(N=14)$ & 0 & 0.0 & 14 & 46.7 & \multirow{2}{*}{28.28} & $<0.001$ \\
\hline & No $(\mathbf{N}=66)$ & 50 & 100.0 & 16 & 53.3 & & (HS) \\
\hline \multirow{2}{*}{ Bladder injury } & Yes $(N=40)$ & 0 & 0.0 & 10 & 33.3 & \multirow{2}{*}{19.04} & $<0.001$ \\
\hline & No $(\mathbf{N}=16)$ & 50 & 100.0 & 20 & 66.7 & & (HS) \\
\hline
\end{tabular}

Table (5): The relationship between loss of retroplacental sonolucent zone and (maternal and fetal peripartum complications).

\begin{tabular}{|c|c|c|c|c|c|c|c|}
\hline \multirow[b]{2}{*}{ peripartum complications } & \multirow[t]{2}{*}{$\begin{array}{l}\text { Loss of retropl. } \\
\text { Sonolutent zone }\end{array}$} & \multicolumn{2}{|c|}{$\begin{array}{l}\text { Yes } \\
(N=20)\end{array}$} & \multicolumn{2}{|c|}{$\begin{array}{l}\text { No } \\
(\mathrm{N}=60)\end{array}$} & \multirow{2}{*}{$\begin{array}{l}X^{2} / \\
\text { FET }\end{array}$} & \multirow{2}{*}{$\mathbf{P}$} \\
\hline & & No. & $\%$ & No. & $\%$ & & \\
\hline \multirow{2}{*}{ Maternal mortality } & Yes $\quad(\mathrm{N}=2)$ & 2 & 10.0 & 0 & 0.0 & \multirow{2}{*}{6.15} & 0.01 \\
\hline & No $(\mathbf{N}=78)$ & 18 & 90.0 & 60 & 100.0 & & (S) \\
\hline \multirow{2}{*}{ CS hysterectomy } & Yes $(N=15)$ & 13 & 65.0 & 2 & 3.3 & \multirow{2}{*}{37.44} & $<0.001$ \\
\hline & No $(\mathbf{N}=65)$ & 7 & 35.0 & 58 & 96.7 & & (HS) \\
\hline \multirow{2}{*}{ Blood transfusion } & Yes $(N=32)$ & 20 & 100.0 & 12 & 20.0 & \multirow{2}{*}{40.0} & $<0.001$ \\
\hline & No $(\mathbf{N}=48)$ & 0 & 0.0 & 48 & 80.0 & & (HS) \\
\hline \multirow{2}{*}{ ICU } & Yes $(N=14)$ & 13 & 65.0 & 1 & 1.7 & \multirow{2}{*}{41.67} & $<0.001$ \\
\hline & No $(\mathbf{N}=66)$ & 7 & 35.0 & 59 & 98.3 & & (HS) \\
\hline \multirow{2}{*}{ Bladder injury } & Yes $(N=40)$ & 10 & 50.0 & 0 & 0.0 & \multirow{2}{*}{34.28} & $<0.001$ \\
\hline & No $(\mathbf{N}=16)$ & 10 & 50.0 & 60 & 100.0 & & (HS) \\
\hline \multirow{2}{*}{ Neonatal death } & Yes $(N=6)$ & 3 & 15.0 & 3 & 5.0 & \multirow{2}{*}{21.62} & \multirow{2}{*}{0.14} \\
\hline & No $(N=74)$ & 17 & 85.0 & 57 & 95.0 & & \\
\hline \multirow{2}{*}{ NICU } & Yes $(\mathrm{N}=21)$ & 13 & 65.0 & 8 & 13.3 & \multirow{2}{*}{20.68} & $<0.001$ \\
\hline & No $(N=59)$ & 7 & 35.0 & 52 & 86.7 & & (HS) \\
\hline \multirow{2}{*}{ Preterm labour } & Yes $(\mathrm{N}=24)$ & 14 & 70.0 & 10 & 16.7 & \multirow{2}{*}{20.31} & $<0.001$ \\
\hline & No $(N=56)$ & 6 & 30.0 & 50 & 83.3 & & (HS) \\
\hline
\end{tabular}


Table (6): The relationship between Rt. PI of uterine artery Doppler and maternal and fetal peripartum complications.

\begin{tabular}{|c|c|c|c|c|c|}
\hline Uterine artery & & Rt. PI & & & \\
\hline Peripartum complications & & No. & Mean \pm SD & $\mathbf{t}$ & $\mathbf{P}$ \\
\hline Maternal mortality & $\begin{array}{l}\text { Yes } \\
\text { No }\end{array}$ & $\begin{array}{c}2 \\
78\end{array}$ & $\begin{array}{l}0.67 \pm 0.25 \\
1.19 \pm 0.43\end{array}$ & 1.72 & 0.08 \\
\hline CS hysterectomy & $\begin{array}{l}\text { Yes } \\
\text { No }\end{array}$ & $\begin{array}{l}15 \\
65\end{array}$ & $\begin{array}{l}0.96 \pm 0.38 \\
1.23 \pm 0.43\end{array}$ & 2.23 & $\begin{array}{l}0.02 \\
(\mathrm{~S})\end{array}$ \\
\hline Blood transfusion & $\begin{array}{l}\text { Yes } \\
\text { No }\end{array}$ & $\begin{array}{l}32 \\
48\end{array}$ & $\begin{array}{l}1.08 \pm 0.41 \\
1.24 \pm 0.43\end{array}$ & 1.64 & 0.10 \\
\hline ICU & $\begin{array}{l}\text { Yes } \\
\text { No }\end{array}$ & $\begin{array}{l}14 \\
66\end{array}$ & $\begin{array}{l}0.90 \pm 0.40 \\
1.24 \pm 0.42\end{array}$ & 2.71 & $\begin{array}{c}0.008 \\
(\mathrm{~S})\end{array}$ \\
\hline Bladder injury & $\begin{array}{l}\text { Yes } \\
\text { No }\end{array}$ & $\begin{array}{l}40 \\
16\end{array}$ & $\begin{array}{l}0.87 \pm 0.41 \\
1.22 \pm 0.42\end{array}$ & 2.47 & $\begin{array}{c}0.01 \\
(\mathrm{~S})\end{array}$ \\
\hline Neonatal death & $\begin{array}{l}\text { Yes } \\
\text { No }\end{array}$ & $\begin{array}{c}6 \\
74\end{array}$ & $\begin{array}{l}1.20 \pm 0.24 \\
1.18 \pm 0.44\end{array}$ & 0.008 & 0.98 \\
\hline NICU & $\begin{array}{l}\text { Yes } \\
\text { No }\end{array}$ & $\begin{array}{l}21 \\
59\end{array}$ & $\begin{array}{l}1.07 \pm 0.48 \\
1.22 \pm 0.41\end{array}$ & 1.83 & 0.17 \\
\hline Preterm labor & $\begin{array}{l}\text { Yes } \\
\text { No }\end{array}$ & $\begin{array}{l}24 \\
56\end{array}$ & $\begin{array}{l}1.12 \pm 0.42 \\
1.20 \pm 0.44\end{array}$ & 0.59 & 0.44 \\
\hline
\end{tabular}

Table (7): The relationship between Rt. RI of uterine artery Doppler and maternal and fetal peripartum complications.

\begin{tabular}{|c|c|c|c|c|c|}
\hline Peripartum complications & Uterine artery & $\begin{array}{l}\text { Rt. RI } \\
\text { NO. }\end{array}$ & Mean \pm SD & $\mathbf{t}$ & $\mathbf{P}$ \\
\hline Maternal mortality & $\begin{array}{l}\text { Yes } \\
\text { No }\end{array}$ & $\begin{array}{c}2 \\
78\end{array}$ & $\begin{array}{l}0.68 \pm 0.22 \\
0.67 \pm 0.25\end{array}$ & 1.46 & 0.14 \\
\hline CS hysterectomy & $\begin{array}{l}\text { Yes } \\
\text { No }\end{array}$ & $\begin{array}{l}15 \\
65\end{array}$ & $\begin{array}{l}0.54 \pm 0.19 \\
0.71 \pm 0.22\end{array}$ & 2.69 & $\begin{array}{c}0.009 \\
(\mathrm{~S})\end{array}$ \\
\hline Blood transfusion & $\begin{array}{l}\text { Yes } \\
\text { No }\end{array}$ & $\begin{array}{l}32 \\
48\end{array}$ & $\begin{array}{l}0.61 \pm 0.21 \\
0.72 \pm 0.21\end{array}$ & 2.32 & $\begin{array}{l}0.02 \\
(\mathrm{~S})\end{array}$ \\
\hline ICU & $\begin{array}{l}\text { Yes } \\
\text { No }\end{array}$ & $\begin{array}{l}14 \\
66\end{array}$ & $\begin{array}{l}0.52 \pm 0.18 \\
0.71 \pm 0.21\end{array}$ & 3.17 & $0.002(\mathrm{~S})$ \\
\hline Bladder injury & $\begin{array}{l}\text { Yes } \\
\text { No }\end{array}$ & $\begin{array}{l}40 \\
16\end{array}$ & $\begin{array}{l}0.49 \pm 0.16 \\
0.70 \pm 0.21\end{array}$ & 3.08 & $\begin{array}{c}0.003 \\
(\mathrm{~S})\end{array}$ \\
\hline Neonatal death & $\begin{array}{l}\text { Yes } \\
\text { No }\end{array}$ & $\begin{array}{c}6 \\
74\end{array}$ & $\begin{array}{l}0.69 \pm 0.19 \\
0.68 \pm 0.22\end{array}$ & 0.01 & 0.90 \\
\hline NICU & $\begin{array}{l}\text { Yes } \\
\text { No }\end{array}$ & $\begin{array}{l}21 \\
59\end{array}$ & $\begin{array}{l}0.62 \pm 0.22 \\
0.70 \pm 0.22\end{array}$ & 2.17 & 0.14 \\
\hline Preterm labour & $\begin{array}{l}\text { Yes } \\
\text { No }\end{array}$ & $\begin{array}{l}24 \\
56\end{array}$ & $\begin{array}{l}0.62 \pm 0.20 \\
0.70 \pm 0.22\end{array}$ & 2.38 & 0.12 \\
\hline
\end{tabular}

Table (8): Logistic regression analysis for the predictors of C.S hystrectomy of the studied group.

\begin{tabular}{llll}
\hline $\begin{array}{l}\text { C.S hystrectomy } \\
\text { Predictors (n=80) }\end{array}$ & Beta & adjusted $\mathbf{R}^{2}$ & $\mathbf{P}$ \\
\hline Lt. RI uterine artery & -0.798 & 0.68 & $0.04(\mathrm{~S})$ \\
\hline
\end{tabular}




\section{Conclusion}

the gray scale and color Doppler ultrasound have a high diagnostic value in the diagnosis of placenta previa and placenta previa accreta by certain placental morphological features, Including loss of retroplacental clear zone, thinning of myometrial thickness, Intraplacental lacunae, Intraplacental vascularity and exophytic mass into bladder space. Ultrasound is helpful and non-invasive tool in prediction of maternal and fetal outcome. High grade of placental lacunae and abnormal placental vascularity were highly associated with maternal and fetal complications. Uterine artery Doppler PI and RI is also useful in prediction of maternal complications and were not of value in prediction of fetal complications of placenta previa and placenta previa accreta.

\section{References}

1. Lorenz RP (2013). What is new in placenta accreta? Best articles from the past year. Obstet Gynecol.;121(2 Pt 1):375-376.

2. Collins, S. L., Chantraine, F., Morgan, T. K., and Jauniaux, E (2018). Abnormally adherent and invasive placenta: a spectrum disorder in need of a name. Ultrasound in obstetrics \& gynecology : the official journal of the International Society of Ultrasound in Obstetrics and Gynecology, 51(2), 165-166.

3. Selman A. E (2016). Caesarean hysterectomy for placenta praevia/accreta using an approach via the pouch of Douglas. BJOG: an international journal of obstetrics and gynaecology, 123(5), 815-819.

4. Shamshirsaz AA, Fox KA, Erfani H, Clark SL, Salmanian B, Baker BW, et al., (2016). Multidisciplinary team learning in the management of the morbidly adherent placenta: outcome improvements over time. Am J Obstet Gyneco ; (216:612.e1-5).

5. Poon LC, Volpe N, Muto B, Yu CK, Syngelaki A, Nicolaides KH(2013). Second-trimester uterine artery Doppler in the prediction of stillbirths. Fetal Diagn Ther; 33:28-35.

6. Cho, H., Hwang, H., Kwon, J., Park, Y., \& Kim, Y (2013). Usefulness of uterine artery Doppler velocimetry in diagnosing placenta accreta in placenta previa patients. Ultrasound in Obstetrics \& Gynecology,;42(s1), 41-41

7. Heller DS, Baergren RN and Thaker HM (2013). Placental release or disposal? Experiences of perinatal pathologists. Pediatr Dev Pathol; 16(5): 327-330.

8. Comstock CH (2005). Antenatal diagnosis of placenta accreta: a review. Ultrasound Obstet Gynecol; 26: 89-96.

9. Comstock CH, Love Jr, Bronsteen RA, Lee W, Vettraino IM, Huang RR, et al., (2004). Sonographic detection of placenta accreta in the second and third trimesters of pregnancy. Am J Obstet Gynecol.;190:1135- 1140.

10. Esakoff TF, Little SE, Cheng YW, Sparks TN and Caughey AB (2011). The effect of cesarean delivery rates on the future incidence of placenta previa, placenta accreta, and maternal mortality. J Matern Fetal Neonatal Med; 24(11):1341-1346.

11. Woodring TC, Klauser CK, Bofill JA, Martin RW, Morrison JC (2011). Prediction of placenta accreta by ultrasonography and color Doppler imaging. J Matern Fetal Neonatal Med; 24(1): 118-121.

12. Yoon, S.-Y., You, J. Y., Choi, S.-J., Oh, S., Kim, J.-H., and Roh, C.-R. A (2014). Combined ultrasound and clinical scoring model for the prediction of peripartum complications in pregnancies complicated by placenta previa. European Journal of Obstetrics \& Gynecology and Reproductive Biology, 180, 111-115.

13. Kwak DW, Kwon JY, Kim YH and Park YW (2008). Is it possible to predict placenta accreta 
by uterine artery Doppler velocimetry in placenta previa? Chicago, USA.

14. Cho, H. Y., Hwang, H. S., Jung, I., Park, Y. W., Kwon, J.-Y., and Kim, Y. H. (2015). Diagnosis of Placenta Accreta by Uterine Artery Doppler Velocimetry in Patients With Placenta Previa. Journal of Ultrasound in Medicine,; 34 (9), 1571 1575. doi:10.7863/ultra.15.14.08039

15. Sumigama S, Itakura A, Ota T, Okada M, Kotani T, Hayakawa H, et al. (2007). Placenta previa increta/percreta in Japan: a retrospective study of ultrasound findings, management and clinical course. J Obstet Gynaecol Res; 33: 606-611.

16. Rossi AC, Lee RH and Chmait RH. (2010). Emergency postpartum hysterectomy for uncontrolled postpartum bleeding: a systematic review. Obstet Gynecol;115(3): 637-644.

17. Creasy RK, Resnik R, Iams J and Lockwood C. (2014). Placenta previa, placenta accreta, abruptio placentae and vasa previa. Creasy and Resnik's Maternal-Fetal Medicine: prinicples and practice. 7th ed: Philadephia, PA;(723-742).

18. Yang JI, Lim YK, Kim HS, Chang KH, Lee JP and Ryu HS. (2006). Sonographic findings of placental lacunae and the prediction of adherent placenta in women with placenta previa totalis and prior Cesarean section. Ultrasound Obstet Gynecol; 28:178-182.

19. Hamada S, Hasegawa J, Nakamura M, Matsuoka R, Ichizuka K, Sekizawa A, et al. (2011). Ultrasonographic findings of placenta lacunae and a lack of a clear zone in cases with placenta previa and normal placenta. Prenat Diagn; (31:1062-1065).
20. Hasegawa J, Matsuoka R, Ichizuka K, Mimura T, Sekizawa A, Farina A, et al. (2009). Predisposing factors for massive hemorrhage during Cesarean section in patients with placenta previa. Ultrasound Obstet Gynecol ;34: 80-84.

21. Jamal A, Abbasalizadeh F, Vafaei H, Marsoosi V, and Eslamian L. (2013). Multicenter screening for adverse pregnancy outcomes by uterine artery Doppler in the second and third trimester of pregnancy. Med Ultrason; 15: 95- 100.

22. Albaiges, G. (2000). One-stage screening for pregnancy complications by color Doppler assessment of the uterine arteries at 23 weeks' gestation. Obstetrics \& Gynecology,;96(4), 559564.

23. Ghosh, G., Breborowicz, A., Brązert, M., Maczkiewicz, M., Kobelski, M., Dubiel, M., et al., (2006). Evaluation of third trimester uterine artery flow velocity indices in relationship to perinatal complications. The Journal of MaternalFetal \& Neonatal Medicine,;19(9), 551-555.

24. Abdel Moniem, A. M., Ibrahim, A., Akl, S. A., Aboul-Enen, L., and Abdelazim, I. (2015). A. Accuracy of three-dimensional multislice view Doppler in diagnosis of morbid adherent placenta. Journal of the Turkish German Gynecological Association,;16(3), 126-136.

25. Salavati, N., Smies, M., Ganzevoort, W., Charles, A. K., Erwich, J. J., Plösch, T., et al., (2019). The Possible Role of Placental Morphometry in the Detection of Fetal Growth Restriction. Frontiers in physiology, 2019;9, 1884.

To cite this article: Shimaa F. Eliwa, Mahmoud Abdel Fatah, Mohamed A. El Noury, Mostafa A. El Sayed. Uterine Artery Doppler and Placental Morphological Features as Predictors of Peripartum Complications in Placenta Previa and Placenta Previa Accreta. BMFJ; 38(1): 14-26. DOI: $10.21608 /$ bmfj.2021.24667.1218 